\title{
EL ALZAMIENTO MODERADO-FUERISTA DE OCTUBRE DE 1841. EL CASO DE LA VILLA DE BILBAO
}

\author{
por \\ JAVIER PÉREZ NÚÑEZ
}

Universidad Autónoma de Madrid

RESUMEN: El desplazamiento del poder de los moderados con el movimiento revolucionario progresista del verano de 1840 causó un hondo disgusto a los dirigentes fueristas, dominantes en las instituciones forales de las Vascongadas, ya que suponía poner fin a una política, sobre todo foral pero también nacional, totalmente concordante con sus intereses y principios ideologicos. Tanto en una como en otra el papel ejercido por la reina gobernadora, María Cristina, habia sido clave al convertirse en lider de esas tendencias conservadoras, por lo que su renuncia a la regencia significaba la pérdida de la pieza fundamental de su engranaje político.

Siendo, por tanto, los fueristas la version vascongada del moderantismo, se convirtieron en uno de los pilares de los proyectos de conspiración conservadora. A este respecto, Bilbao ocupo un papel de primer orden porque su burguesia era un componente esencial del bloque dirigente provincial, residenciado, además, en esa villa y porque aqui se trasladaron, tras su desalojo del poder, ilustres politicos moderados, produciéndose una total simbiosis de los postulados de los miembros de la misma familia politica, haciendo de Bilbao la capital en el interior del Reino del movimiento reaccionario de octubre de 1841 , que fracasó estrepitosamente.

Palabras clave. Edad Contemporánea, siglo xux, España, País Vasco, Bilbao, Eistoria Social, Conservadores, Constitución, Fueros.

ABSTRACT: The displacement of the conservative group from governance due to the revolutionary progresive movement that took place during the summer of 1840 , generated deep uneasiness among the statutory leaders, who up to that moment had dominated the statutory institutions in the Basque provinces, as this meant the end of the policy, mainly statutory but also national, totally concordant with their interest and the ideological principles. In both cases, the role performed by the regent queen, $M .{ }^{a}$ Cristina, had been decissive, as she had become leader of these conservative tendencies, thus her abdication meaning the loss of the fundamental piece of the political interlocking. 
Therefore, as the statutories were the Basque version of the conservatism, they became one of the main supports of the conservative conspiracy projects. To this respect, the city of Bitbao played a first-rate role as its bourgeosie was an essential member of the provincial leadership group, furtherrmore with residence in there, and also because most of the distinguished from governance, which produced a total symbiosis of the postulates of the members of the same political family, this converting Bilbao into the capital, in the interior of the kingdom, of the reactionary movement of October 1841, that, in fact, was a clamorous failure.

KEY WORDS: Contemporary Age, 19th century, Spain, the Basque Country, Bilbao, Social History, conservatives, Constitution, Statutes.

«(...) Los llamados moderados querían el monopolio del mando absoluto con un simulacro de gobierno constitucional, y los oligarcas fueristas querian para si el monopolio del mando en las provincias, con apariencias de elección popular. Tan corta es la diferencia entre las miras de unos y de otros que se puede decir que es una sola y misma cosa con diferentes apellidos. (...).

(MARLIANI, Enmanuelle, La Regencia de Baldomero Espartero, Conde de Luchana, Duque de la Victoria y de Morella, y los sucesos que la prepararon, Madrid, 1870, pag. 62)

En marzo de 1840 José María Calatrava manifestaba en el Congreso de los Diputados que en Vizcaya se habla degradado la dignidad real al no haber sido reconocida Isabel II como «Reina constitucional de las Españas», sino como "Señora de Vizcaya» '. Era verdad que en esta provincia la reina habia sido proclamada en las Juntas generales de diciembre de 1839, con el ceremonial de costumbre, como Sefora de Vizcaya, pero ello no denotaba deslealtad alguna hacia la institución monárquica como quería significar ese diputado progresista. Al contrario, tras el Convenio de Vergara y, sobre todo, tras la aprobación de la ley de 25 de octubre de 1839 , confirmatoria de los fueros, se inició un camino hacia la identificación de los fueros con la Monarquía de Isabel II, de la reina gobernadora con esa confirmación.

La progresiva elevación de la dignidad real, paralela al proceso de encumbramiento de los fueros, era el único medio que tenían los dirigentes fueristas vizcaínos que, dominantes en las instituciones forales, habían seguido la causa de la reina en la guerra carlista, para intentar atraer a la mayoria de la población, que había mantenido su fidelidad al pretendiente.

1 Diario de Sesiones del Congreso de los Diputados (DSC), 25-III-1840, núm. 29, págs. 658-659.

Hispania, LVI2, núm. 193 (1996) 565-586 
Para ello, para tratar de conseguir el desplazamiento de esta fidelidad a la reina, para convertir la causa de la reina en la causa de los vizcaínos, procedieron, mediante una simbiosis entre el pensamiento tradicionalista y liberal, a la transformación de la Monarquía y de los fueros en cláusulas de intangibilidad, en realidades supraconstitucionales; de forma que ala Monarquía devenía así en un axioma de organización política para el presente, a la vez que se identificaba con el carácter nacional [vizcaíno (vasco)] en la proyección del pasado" ${ }^{2}$.

No obstante, para la clase liberal-fuerista - no para el pueblo vizcaino, «que no se ocupaba de cuestiones abstractas y brillantes teorías" ${ }^{3}-$ la adhesión al trono era algo política e ideológicamente más profundo: «en la constitución de Vizcaya es natural el respeto al Trono y nosotros no tenemos ciertas falsas doctrinas democratizadoras de las que ahora corren; no nos desdeñamos en respetar la soberania [regia], porque sabemos que la soberanía [regia] respeta nuestros fueros y privilegios» ${ }^{4}$. De esta manera, al principio de la soberanía nacional contraponían el de la soberanía compartida de los moderados, porque era el único que podía garantizar la subsistencia del régimen foral. Así, si los moderados colocaban a las Cortes y a la Monarquía por encima de la Constitución, como instancias preexistentes a la ley constitucional (o constituyentes) que obtenian su legitimidad en la historia, los fueristas situaban a la Junta general y al trono, de tal forma que «los partidarios más ardientes de Isabel II no reconocen en poder alguno del Estado la facultad de alterar los fueros sin la concurrencia libre de la Junta general" s. En definitiva, —decía El Vascongado, órgano de prensa del liberalismo fuerista vizcaíno- "los fueros de esas provincias [Vascongadas] son aisladamente otras constituciones tan completas como la Constitución [de 1837]" ' ${ }^{6}$ e incluso la superaban (si tenemos en cuenta lo que apuntaron los representantes de las mismas en la conferencia celebrada en Bilbao en febrero de 1840), ya que «los fueros en las provincias Vascongadas constitúan un sistema perfecto de régimen, gobierno y administracion, bajo el cual se habian obtenido en estas montañas, sin perjuicio de la Monarquía, todas las ventajas del estado social, ?

Pero esa vinculación a la Monarquía, esa adhesión a María Cristina se debía, sobre todo, a la ostensible inclinación de ésta en favor de los moderados. La

\footnotetext{
2 cirujano marin, Paloma, elorriaga PLANes, Teresa y PEREZ Garzon, Sisinio, Historiografia y nacionalismo español, 1834-1868, Madrid 1985, pág. 101.

3 Archivo de la Diputación Foral de Bizkaia (ADFB). Libros de acuerdos de Jas Diputaciones generales, Regimientos generales y Juntas generales. Acta de la Diputación foral vizcaina, 8-VI1840.

4 DSC, 26-1П-1840, núm. 30, pág. 681. Intervención de Valentín Olano, diputado suplente por Guipúzcoa.

5 Archivo General del Señorío de Bizkaia (AGSB). Régimen Foral, reg. 2 leg. 1. Acta de la Diputación foral vizcaína, 16-1-1840.

6 El Vascongado, 1-IX-1840, núm. 8.

7 ADFB. Libros Históricos, núm. 2. Conferencia de las provincias Vascongadas, Bilbao, 8II.1840.
}

Hispania, LVV/2, ním. 193 (1996) 565-586 
reina gobernadora se había constituido en jefe y cabeza de un partido ${ }^{8}$, al que se debía no sólo la iniciativa de la legalización del hecho foral, sino su materialización en el sentido requerido por los fueristas. Gracias a él las provincias vascas habian recuperado sus fueros, gracias a él las Diputaciones forales estaban consiguiendo una posición hegemónica hasta entonces jamás alcanzada.

Esa línea hacia el fortalecimiento foral, como es sabido, se asienta en la ley de 25 de octubre de 1839 que, clausurando las expectativas abiertas en el convenio de Vergara, confirmaba, en su artículo primero, los fueros de las provincias vascas, «sin perjuicio de la unidad constitucional de la Monarquía», y arbitraba, en su artículo segundo, la necesidad de proceder a las modificaciones indispensables que los hicieran compatibles con el interés general de la nación y de la Constitución de la Monarquía, autorizando al gobierno para resolver las dudas que, entretanto, pudieran suscitarse. Pues bien, sustentándose en esta autorización, el ejecutivo de Evaristo Pérez de Castro-Lorenzo Arrazola dictó el real decreto de 16 de noviembre de 1839, por el que se restablecian las instituciones básicas de los regimenes forales (Juntas y Diputaciones forales, y ayuntamientos tradicionales), manteniendo dos instancias devaluadas de la administración provincial de régimen común (los jefes políticos, que quedaban como corregidores políticos, y las Diputaciones provinciales).

Con esa visión tan amplia de la foralidad y con esa visión tan estrecha de la unidad constitucional, reducida a la existencia «de un solo Rey constitucional para todas las provincias, un mismo Poder legislativo, una representación nacional común" ', los moderados comenzaron su política con relación a esas provincias, que se iba a caracterizar por considerar la "cuestión foral" un asunto a resolver por el ejecutivo ${ }^{10}$, ya que su arreglo definitivo era algo que se debía desenvolver en el tiempo. Así, no obstante en ese decreto se dispusiera que las Vascongadas y Navarra nombraran comisionados, con los cuales pudiera conferenciar el gobierno para cumplimentar el artículo segundo de la ley confirmatoria de los fueros, posponían su resolución a la transformación conservadora del régimen constitucional que, mediante la restricción de la participación política, limitación de la libertad de imprenta, control gubernativo de la administración local, reducción del poder de la milicia nacional, etc. perseguía el desplazamiento de los progresistas de las instancias en las que mantenfan la hegemonía. Mientras tanto, no sólo dejaron a los fueristas libertad en sus iniciativas modificadoras o restauradoras, sino que acabaron por confiarles la representación del gobierno en sus provincias.

\footnotetext{
8 LAFUENTE, Modesto, Historia General de España desde los tiempos primitivos hasta la muerte de Femando VII. Continuada desde dicha época hasta la muerte de don Alfonso XII por don Juan Valera con la colaboración de Andrés Borrego u otros, y hasta la mayor edad de don Alfonso XIII por Gabriel Maura y Gamazo, vol. XXII, Barcelona 1922-1927, pág. 81.

9 Diario de Sesiones del Senado (DSS), 19-X-1839. Intervención del ministro de Gracia y Justicia, Lorenzo Arrazola.

10 PORTLLL VALDES, José María, Los poderes locales en la formación del régimen foral. Guipúzcoa (1812-1850), Bilbao 1987, págs. 101-102.
}

Hispania, LVI2, núm. 193 (1996) 565-586 
Esta transformación de los fueristas en los interlocutores políticos entre el poder central y la población vascongada se debió a que, al margen de la cuestión foral, eran ideológicamente afines, eran la versión vascongada del moderantismo, de modo que, en el ámbito del país, ambos términos son prácticamente intercambiables ". Así, participando de los mismos ideales, del rechazo de la soberanía nacional como principio constituyente de la nación, de la reserva del poder político a las clases propietarias e ilustradas y de la supeditación de la libertad, o mejor de las libertades, al mantenimiento del orden público, los fueristas, garantizando la salvaguardia de esos presupuestos en las Vascongadas, prestaban todo su apoyo en las contiendas parlamentarias a sus «amigos políticos» 12 .

Lógicamente esa interrelación moderados-fueristas y la situación de ella derivada chocaba con los planteamientos de los progresistas, para quienes, no estando dispuestos a ser anulados como fuerza política, era preciso que el País Vasco se homologara con el resto del Estado, dejando de ser la punta de lanza del programa conservador. Por eso exigían que se cumpliera en todos sus términos la ley de 25 de octubre de 1839 , para conciliar definitivamente los regimenes forales con la unidad constitucional, pero interpretando ésta según los precedentes establecidos en la ley de 19 de septiembre de 1837, es decir, haciendo que la Constitución de la Monarquía rigiera en las provincias vascas como en las demás de la nación. De ahí que rechazaran tajantemente el real decreto de 16 de noviembre de 1839 porque, al limitarse simplemente a la confirmación foral, vulneraba el principio de la unidad constitucional, quedando las Vascongadas al margen del Codigo político del Estado ${ }^{13}$.

Por eso las noticias de los levantamientos progresistas del verano de 1840, consecuencia lógica de la política hacia el monopolio del poder ejercida por el partido moderado con la total connivencia de la reina gobernadora ${ }^{14}$, causaron un hondo disgusto a los fueristas. Tanto fue así, que siendo bastante exigua la influencia del liberalismo progresista en las Vascongadas, con la excepción de la ciudad de San Sebastián, ese movimiento revolucionario, que concluyó con la renuncia a la regencia de María Cristina y con el establecimiento del ministerio-regencia progresista bajo la presidencia de Baldomero Espartero, no sólo no se extendió a estas provincias, sino que en sus clases

\footnotetext{
11 FERnandez SEbastian, Javier, La génesis del fuerismo. Prensa e ideas políticas en la crisis del Antiguo Régimen (País Vasco, 1750-1840), Madrid 1991, págs. 473 y 476.

12 ORTIZ DE ORRUÑo, José María y PORTJLLo valDES, José María, «La foralidad y el poder provincial»: Historia Contemporánea 4 (1990) 114 y PEREZ NUÑEZ, Javier, «El País Vasco a mediados del siglo XIX (1839-1868): la realización de la utopía conservadora), en FERNANDEZ ALBADALEJo, Pablo y ortegA, Margarita (eds.), Antiguo Régimen y Liberalismo (Homenaje a Miguel Artola), 3. Política y Cultura, Madrid 1995, págs. 293-294.

13 Para el contexto y distintos planteamientos en tomo a ley de 25 de octubre de 1839 y su desamollo son de especial interés los trabajos recogidos en AGIRREAZKUENAGA, Joseba y URQUIJo corriA, José Ramón (eds.), I50 años del Convenio de Bergara y de la ley del 25-X-1839, Vitoria-Gasteiz, 1990.

14 PIRALA, Antonio, Historia de la guerra civil y de los partidos liberal y carlista, vol. VI, Madrid 1984. pág. 199.
} 
dirigentes se observó una clara resistencia pasiva al mismo ${ }^{15}$. Así, las Diputaciones vascongadas, reunidas en Vitoria el 15 de septiembre, elevaron al virrey y general en jefe del ejército del norte, Felipe Ribero, una exposición en la que garantizaban el mantenimiento del orden, utilizando para ello sus propios recursos, a pesar de «las pruebas de deslealtad que se estaban produciendo en las otras provincias del Estadon y a pesar, sobre todo, de alas circunstancias críticas que afligian a la Monarquían ${ }^{16}$.

Esa visión contrastaba con la de la ciudad de San Sebastián, en donde su burguesía, distanciada del resto de la provincia desde 1834 y de forma terminante desde la confirmación de los fueros, recibió con alborozo el triunfo del pronunciamiento, ya que, significando el acceso al poder de aquellos que coincidían en el mismo rechazo al decreto restaurador de 16 de noviembre de 1839 . abria la vía para que se observase la unidad constitucional, estableciendo una nueva sociedad liberal e igualitaria ${ }^{17}$. Por contra, en la villa de Bilbao, su burguesía no sólo había limado al máximo las diferencias seculares con la aristocracia rural, sino que, identificada con el liberalismo fuerista, era un componente esencial del bloque dirigente provincial. Así fue desde esta villa de donde la reina madre, ya en exilio, recibió las primeras muestras de apoyo: de una parte, de su Ayuntamiento, que el 24 de octubre le remitió una carta en la que, considerando que en la ausencia momentánea que se imponía «le seguirían sin duda los votos de todos los hombres amantes de la libertad de su patria, a la cual quedaría eternamente unida su recuerdos, estimaba que, «entre ellos, quizás no se contaran los últimos los habitantes de la villa” 18; de otra parte, de las Diputaciones forales, que siguiendo el ejemplo de anterior corporación municipal, acordaron, en este mismo lugar el 2 de noviembre, enviarle un mensaje de agradecimiento, en el que, entre otras cosas, le manifestaban:

"(..) Sefiora: Nunca se borrará del corazón de los vascongados la memoria de los beneficios que os debieron durante vuestro generoso gobierno, y la paz que le otorgasteis; y la mano bienhechora con que les concedisteis volver a vivir, con las veneradas y queridas leyes, con las sencillas y patriarcales costumbres con que vivieron y murieron contentos, libres y felices sus padres. (...)" ${ }^{19}$.

is «Un partido se declaró en Bizcaya francamente enemigo del alzamiento de Septiembre», decía ORTZ DE ZARATE, Ramón, «El país vascongado en 1841 y 1856»: Boletín de Comercio 479 (1856) (Cit. SANCHEZ PRIETO, Juan Maria, El imaginario vasco: Representaciones de una conciencia histórica, nacional y políica en el escenario europeo, 1833-1976, Barcelona 1993, pág. 706). No así en Navarra, donde, al igual que en Guipúzcoa, el Ayuntamiento de Pamplona, distanciándose de la Diputación provincial, apoyó el levantamiento, creando la consiguiente Junta de gobiemo (Ref. CAMPO JESUS, Luis del, Pamplona durante la postguerra carlista (1839-1840), Pamplona 1991, págs. 130-136).

16 ADFB. Libros Históricos, núm. 2. Conferencia de las provincias Vascongadas, Vitoria, 15 IX-1840.

17 FERNANDEZ SEBASTIAN, J. op. cit., págs. 490-493 y GARCIA RONDA, Angel, La transformación de la foralidad guipuzcoana (1837-1844), San Sebastián 1991, págs. 57-63.

18 El Vascongado, 30-X-1840, núm. 32.

19 ADFB. Libros Históricos, núm. 2. Conferencia de las provincias Vascongadas, Bilbao, 2-XI1840. Este documento, acordado y firmado por los diputados generales en ejercicio de cada una de

Hispania, LVI/2, nưm. 193 (1996) $565-586$ 
Esta epístola adquirió toda su dimensión política, primero, cuando se hizo público el manifiesto dirigido a la nación por María Cristina, fechado en Marsella el 8 de noviembre, en el que destacaba su actuación como escrupulosamente constitucional, lo que equivalía a poner en entredicho la autoridad del ministerio-regencia ${ }^{20}$. Y después, y sobre todo, cuando el 7 de diciembre desde París contestó a las pruebas de adhesión de las provincias Vascongadas, indicando que:

\begin{abstract}
«(...) La pacificación de la Monarquía, cuya aurora amaneció en los campos de VERGARA, y el afianzamiento de vuestros fueros, son dos actos de mi vida pública en el que descansara siempre con el mayor placer mi memoria. Su recuerdo es grato a mi corazón, como el de las acciones buenas y santas.

(...) Aceptad (...) la palabra que os empeño de no olvidaros jamás, como jamás olvidare a los españoles leales, cualesquiera sea la suerte que me reserve la Providencia en sus impenetrables designios. Yo no puedo olvidar al pueblo magnánimo, que es tan grande en la paz, como en la guerra, que no cuenta a sus enemigos cuando los combate, y que los cuenta uno a uno cuando los abraza; que es el fiel guardador de todos sus juramentos, $y$ que se ha formado una religión del culto que consagra a sus purísimas costumbres y a sus veneradas instituciones.

No; YO NO OS OLVIDARE JAMAS, NOBLES Y LEALES VASCONGADOS. Vosotros ocupáis en mi corazón un lugar tan grande, como el que ocuparéis en la historia..- MARIA CRISTINA." 21
\end{abstract}

Con estos textos, superándose el rango de simple ficción o puro dogmatismo de la union articulada entre el trono y los fueros, se sellaba una especie de pacto de adhesion de los dirigentes fueristas a la causa de la ex-reina gobernadora, confirmadora de los fueros. Esta casi adscripción ${ }^{22}$ fue cobrando todo su valor a medida que fue haciéndose efectiva la política de los progresistas con relación a los regímenes forales de las Vascongadas, que, distanciada del laissez faire, laissez passer mantenido por los moderados, se reducía, en última instancia, a la aplicación en su integridad de la ley de 25 de octubre de 1839. De tal forma, que se acabaron convirtiendo, si no las provincias que puede parecer exagerado, sí sus grupos dominantes, en el soporte profundo de la reacción conservadora: «en las provincias Vascongadas no hay mas que un partido, el de la legitimidad» ${ }^{23}$.

las tres provincias - por Vizcaya, Federico Victoria de Lecea y Manuel Maria de Murga; por Guipúzcoa, conde de Monterrón; y por Alava, marqués de la Alameda - fue redactado por el patricio fuerista alavés, Pedro de Egaña.

20 Este manifiesto de la reina madre como el coetáneo del ministerio-regencia se encuentran reproducidos en las obras citadas de LAFUENTE, M. y PIRALA, A., respectivamente, en el vol. XXII. págs. $76-80 \mathrm{y}$ vol. VI, págs. 220-225.

21 ADFB. Libros de órdenes y circulares de la Diputación. Reales cédulas y escrituras originales, núm. 54.

${ }_{22}$ MUGLCA, José, Carlistas, moderados y progresistas (Claudio Antón de Luzuriaga), San Sebastián 1950 , pág. 258.

23 El Vascongado, 18-XI-1840, núm. 15. 
En la orden de 21 de diciembre de 1840 se recogían los principios básicos de actuación de los progresistas con respecto a la "cuestión foral» de las Vascongadas: de una parte debían eliminarse y, por supuesto, no permitirse que se reprodujeran todas las innovaciones abusivas introducidas por los dirigentes fueristas de los organismos forales; de otra parte, llegar a un arreglo definitivo de su situación de interinidad cumpliendo el artículo segundo de la ley de 25 de octubre de 1839, para lo que, tomando la iniciativa, presentarían a las Cortes inmediatas un proyecto de ley de modificación foral, si bien oyendo antes a las provincias, para lo que se llamaba a sus representantes ${ }^{24}$.

Así, la acción inmediata del gobierno del conde de Luchana se dirigió a que sus mandatos fueran obedecidos en esas provincias. Para ello, en primer lugar, revocó las innovaciones que, de motu propio, se habían introducido en las Vascongadas durante el interregno revolucionario, como era el caso de la administración de justicia de Vizcaya. En segundo lugar, tras un breve periodo en que se aglutinaron los mandos civil y militar en los comandantes provinciales de las Vascongadas, cubrió los cargos de los corregidores políticos con personajes progresistas de confianza y procedío a equipararlos con los demás jefes políticos de la Monarquía, transfiriéndoles atribuciones hasta entonces asumidas por las Diputaciones forales, como era el caso de las de policía. En tercer lugar, ante la posición equívoca mantenida por estas provincias durante el proceso revolucionario y los recelos que de ella derivaban, cré la capitanfa general de las provincias Vascongadas y envió tropas de refuerzo a cada una de ellas para hacer más efectivo su control. En cuarto lugar, abolió, por la orden de 5 de enero de 1841, el pase o uso foral, respecto a las leyes que con la Corona elaborasen las Cortes, respecto a los decretos del gobierno y de las sentencias de los tribunales, ya que degradaba los poderes del Estado y era incompatible con la unidad constitucional.

Regularizada de esa manera la administración interina de las Vascongadas, los progresistas también fueron planteando una serie de medidas concretas con el fin de adecuar algunos aspectos de los regímenes forales que, para ellos, cuestionaban el principio de la unidad constitucional. Así, por un lado, sin trasladar las aduanas de la linea del Ebro (con la salvedad de las de Navarra) pusieron un mayor empeño en la inclusión de las Vascongadas en el mercado nacional, promulgando, para ello, una serie de disposiciones, tendentes a la claudicación de estas provincias en favor de la misma, como serian la limitación del beneficio de bandera y la supresión del depósito comercial de la villa de Bilbao, y la derogación del sistema arancelario proteccionista establecido tras la guerra por la Diputación foral de Vizcaya. Por otro lado, este mismo talante más enérgico también se transfirió al ramo de las contribuciones generales, reiterándose las exigencias no sólo para que se abonaran los cupos asignados, sino también de los anteriores no satisfechos desde 1835. Por último, sin introducir innovación alguna en el sistema de elecciones gene-

24 AGSB.Régimen Foral, reg. 2 leg. 1. Comunicación del corregidor politico a la Diputación foral de Vizcaya, 24-XII-1840.

Hispania, LV1/2, núm. 193 (1996) 565-586 
rales, potenciaron el desarrollo del ayuntamiento constitucional, que abría mayores cauces a la participación ciudadana, poniendo en cuestión al ayuntamiento foral, restringido a unos pocos notables locales, y con él a todo el sistema foral.

Paralelamente el ejecutivo progresista se propuso dar cumplimiento al artículo segundo de la ley confirmatoria de los fueros. Para ello, ante la negativa de los dirigentes fueristas a entrar en arreglo foral alguno, realizó de forma unilateral distintos trabajos, que quedaron definitivamente plasmados en el proyecto de ley de 16 de octubre de 1841, cuyos principios eran miméticos a los establecidos para Navarra en la ley de 16 de agosto de ese año, reduciéndose a los siguientes: $11^{\circ}$ ) Se establecería en cada una de las Vascongadas una Diputación provincial que, compuesta y elegida según la legislación general, asumiría las atribuciones de la Junta y Diputación general suprimidas. Además de estas funciones, indicadas sobre todo a la administración económica interior, gozaría de las facultades convenientes para cubrir los cupos del servicio militar, que proporcionalmente le correspondieran, y las cuotas que, de las contribuciones generales, se le asignaran, así como para distribuir los gastos de culto y clero que estarian a cargo de la provincia; $2 .^{\circ}$ ) Los ayuntamientos se homologarían a los de régimen común, tanto en cuanto al sistema de elección como en cuanto a las atribuciones; $3^{\circ}$ ) Habría un jefe político, presidente de la Diputación, que tendrá todas las atribuciones conferidas a los de las demás provincias, salvo las propias de la corporación provincial; $4 .^{\circ}$ ) La administración de justicia se equipararía en orden y procedimiento a la general; $5 .^{\circ}$ ) Se trasladarian las aduanas a las costas y fronteras ${ }^{25}$.

La política foral de los progresistas, calificada por los fueristas como una clara vulneración al Convenio de Vergara y a la ley de 25 de octubre de 1839 , porque, al confundir el principio de la unidad constitucional con la perfecta nivelación, reducía la modificación foral a una simple destrucción del régimen particular de las Vascongadas ${ }^{26}$, fue un importante acicate para que éstos mantuvieran latente el carácter insurreccional observado desde el propio cambio político del verano de 1840:

«(...) Ciertamente si para conservar esa herencia se debiera apelar a las armas y probar de nuevo que los vascongados de hoy son dignos descendientes de aquellos cántabros, que sostuvieron tantos años de lucha gigantesca contra el imperio romano en defensa de su independencia, o de los que más tarde por una gloriosa victoria cambiaron el nombre de Padura, todavía hallan sin duda bastantes energías para

25 Sobre la política de los progresistas con relación a las Vascongadas hemos seguido a: LASALA Y COLLADO, Fermin, Ultima etapa de la unidad nacional. Los Fueros vascongados en 1876, vol. I Madrid 1924, págs. 256-266; MARLIANI, Enmanuelle, La Regencia de Baldomero Espartero, Conde de Luchana, Duque de la Victoria y Morella, y los sucesos que la prepararon, Madrid 1870, págs. 57-65; y PEREZ NUNAEZ, Javier, La Diputación Foral de Vizcaya. El régimen foral en la construcción del Estado liberal (1808-1868), Madrid 1996, págs. 275-295.

${ }_{26}$ ADFB. Libros Históricos, núm. 2. Conferencias de las provincias Vascongadas, Vergara, 26/28-I-1841. 
luchar o morir. Pero no es ya cuestión de fuerza, no es ya cuestión de resistencia la nuestra: lo es solamente de pundonor y lealtad. Hay un pacto que los vascongados han cumplido y cumplirán aún; porque la palabra de un pueblo no se empeña jamás en balde. Más si nosotros cumplimos la nuestra, debemos esperar que el Gobierno espaniol, que el hombre que lo preside hoy, cumplirá también la suya. Los proyectos que les atribuyen no pueden sin embargo conducir a este resultado; olvidan demasiado que modificar no es destruir y que cuando más noble y conciliador se manifieste un pueblo, más terrible y profunda debe ser su cólera el día que sea patente para el el lazo tendido a su confianza y buena fe. (...) ${ }^{27}$

Pero, con ser fundamental la evolución de la cuestión foral, no fue el único elemento para mantener alterados los ánimos de las clases dirigentes vascongadas. Así, para éstos el retorno de los moderados al poder —su máxima aspiracion, ya que «siempre que habia habido que sostener los derechos del del pais Vascongado o hacer resaltar su mérito, sus servicios o buena fe, les habían visto anticiparse a sus deseos y exceder en sus esperanzas" ${ }^{28}-$ no podfa significar sólo la vuelta a los momentos más favorables a la foralidad de los años 39 y 40, sino también el regreso a una situación en la que existían mayores garantías para el mantenimiento de orden social, que - según los fueristastenía visos de desbordarse por la influencia perniciosa de las ideas democratizadoras introducidas por los progresistas. De tal manera, que - argumentaba El Vascongado- si «la Constitución peligra y con ella la Corona, nuestros fueros y la sociedad ¿por qué no habremos de defenderlos todos?" 29.

A este respecto, nos parecen francamente ilustrativas las razones aducidas desde la Corte parisina de la ex-reina gobernadora tras el fracaso de la sublevación conservadora como las causantes de ésta. Argumentos, que siendo considerados por el embajador español en Francia, Salustiano de Olozaga, como un «nuevo manifieston de María Cristina y el motivo por el que se suspendiera el pago a ésta de la dotación económica que hasta entonces había disfrutado, se resumen en los siguientes:

"(.) Estas causas se encuentran en los atentados de Barcelona y Valencia; en el vicioso origen del gobierno constituido en Madrid, fruto de la revolución de setiembre; en la usurpación de la autoridad regia; en la descarada injusticia e ilegalidad de las providencias de ese mismo gobierno; en las repetidas y flagrantes infracciones que ha cometido de la Constitución y las leyes; en su imprudente y escandaloso empeño de no guardar cumplidamente la fe jurada en Vergara, hollando como ha hollado los antiguos y respetables fueros de los vascongados y navarros; en el injusto y terrible despojo que ha sufrido la Reina mi Señora de la tutela y curatela de sus excelsas hijas, con asombro y profundo dolor de los leales españoles, que vieron en aquella, como en otras muchas ocasiones, menospreciadas las leyes divinas y humanas, y gravemente ofendidos el decoro y el honor debidos a la Madre de nuestra soberana. Esta serie no inte-

27 El Vascongado, 15-III-I841, núm. 89. Editorial: «Ante las Juntas Generales».

28 lbid., 23-X-1840, núm. 29.

29 lbid., 14-IX-1840, núm. 23.

Hispania, LV1/2, núm. 193 (1996) 565-586 
rrumpida de embates violentos contra todo lo sagrado y digno de respeto en la nación, contra la misma religión santa que profesa y contra el padre común de los fieles; todos estos actos de iniquidad, de opresión y de delirio político que han escandalizado al orbe cristiano y han exasperado cruelmente a la nación, son la principal, la verdadera causa, la causa eficiente de presente alzamiento, que el extremo de tantos males había hecho inevitable.(.)" ${ }^{30}$

Esá inclusión de la particularidad foral en un programa de agravios nacional tuvo su plataforma de desarrollo más importante en la villa de Bilbao, como consecuencia de la presencia en la misma desde el triunfo del alzamiento progresista de un grupo de ilustres políticos moderados (Joaquín Francisco Pacheco, Antonio Alcalá Galiano, Antonio de Escosura y Hevia, Antonio de Benavides, Juan Martín Carromolino, Mariano Valero y Arteta...) y de aristócratas (marqueses de Valmediano, de Santa Cruz, conde de Corres...) ${ }^{31}$. Estos inmediatamente fueron cooptados por la oligarquía fuerista que, aglutinada desde fines de 1839 en torno a la Sociedad Bilbaína y con El Vascongado como 6rgano de prensa ${ }^{32}$, controlaba la Diputación foral, así como el Ayuntamiento y la Junta de Comercio de Bilbao. De tal forma, que acabó produciéndose una clara simbiosis entre moderados y fueristas, convirtiéndose esta villa en uno de los centros fundamentales de la conspiración conservadora, que en julio de 1841 iniciaría definitivamente su andadura.

La conspiración reaccionaria comenzó a fraguarse desde la misma salida de María Cristina y de los muchos personajes adictos al partido moderado que le acompañaron en la emigración ${ }^{33}$. Sin embargo, evidenciada la falta de apoyo popular que un movimiento de ese carácter entonces arrastraría, se atenuaron algo los resentimientos, del que habia sido expresión el manifiesto de Marsella, a la espera de conseguir mayores adhesiones tanto dentro como fuera del Reino. Así, se pueden entender los votos otorgados en mayo de 1841 por los moderados (y fueristas) en favor de la regencia única en manos de Baldomero Espartero, frente a la mayoría de los progresistas inclinados por la regencia trina ${ }^{34}$.

30 Revista de Madrid II $3^{2}$ ser. (1841) 67: Crónica de noviembre, Carta del secretario de la exreina gobemadora, José del Castillo y Ayensa, al embajador de España en París, Salustiano de Olózaga, 24-X-1841.

31 ARELIZA, José María, Historia de una conspiración romántica, Madrid 1950, pág. 49.

32 DIAZ DE MENDIVIL, Anacleto (en Linterna mágica, o sea revista a los partidos políticos de Bil. bao, Madrid 1841, págs. 17-22) otorga a esa sociedad (recreativa», no sin razón, el calificativo de «jovellanista». Frente a ella se organizó desde enero de 1841 el liberalismo progresista vizcaíno en torno a la Sociedad Constitucional, teniendo como órgano de expresión El Vizcaíno Originario.

33 MARICHAL, Carlos (en La revolución liberal y los primeros políticos en España: 1834-1844, Madrid 1980, pág. 224) destaca que «entre los exiliados españoles que recibían pequeñas pensiones del gobierno francés habia 72 ex-ministros y altos funcionarios, cuatro arzobispos y obispos, 573 curas y frailes, 284 empleados públicos, 67 generales del ejército, 915 oficiales del ejército y 4172 of ficiales subalternosy.

34 TOMAS VILLARROYA, Joaquín, «El proceso constitucional (1834-1868)»: La Era isabelina y el sexenio democrático (I834-1874), Madrid 1981, pág. 58.

Hisparia, LVL/2, núm. 193 (1996) 565-586 
Logrado el apoyo de la Corte francesa de Luís Felipe e inclusive el beneplácito del Vaticano, así como de algunos simpatizantes de la causa carlista, la designación en julio de 1841 de Agustín Argüelles como tutor de la reina fue la señal para el inicio de las acciones directas para restablecer la regencia de María Cristina. A este respecto la publicación del nuevo manifiesto fechado en París el 19 de julio, en el que ésta protestaba por el nombramiento de las Cortes de aquel tutor, considerando que era una usurpación de sus legítimos derechos conferidos en el testamento de Fernando VII, fue un llamamiento a la fe monárquica para derrocar a Baldomero Espartero ${ }^{35}$.

María Cristina y sus principales consejeros dirigieron toda la trama conspiratoria desde la especie de Corte en el exilio establecida en el palacio de Courcelles de París, donde aquella residía. Los lugartenientes más destacados de la misma eran los generales Leopoldo O'Donnell, convertido en jefe de la insurrección, y Ramón María Narváez, que quiso quedarse en un segundo plano, a los que se sumaron otros importantes militares antiesparteristas como Diego de León, Manuel Gutiérrez de la Concha, Manuel Montes de Oca, Borso di Carminatti, Manuel Pavía, José Santos de la Hera.... Francisco Cea Bermúdez, Francisco Javier Istúriz, Evaristo Pérez de Castro, Juan Donoso Cortés, Nazario Carriquiri, etc. y los líderes fueristas, entre los que sobresalían Pedro de Egaña, Manuel Urioste de la Herrán y el conde Monterrón, constituían el equipo civil de la revuelta.

Todos ellos, enlazados entre sí con la junta central establecida en París bajo la dirección de Leopoldo O'Donnell, por medio de otra subalterna instituida en Bayona y, vía Bilbao, con otra secreta organizada en Madrid, se distribuyeron las misiones del levantamiento ${ }^{36}$. Este, cuyo plan consistía en una insurrección militar como primera base, debía iniciarse con el alzamiento protagonizado por Leopoldo $O^{`}$ Donnell en el País Vasco, extendiéndose inmediatamente a las guarniciones militares de Cataluña, Aragon y Castilla, y agregándose al mismo los moderados (y fueristas) y los carlistas. En Madrid, objetivo supremo de Ios conjurados, estaban encargados, principalmente, los generales Diego de León y Manuel Gutiérrez de la Concha, de dar un golpe de mano para apoderarse de la reina Isabel II y reunir así, entretanto se restablecía la regencia de María Cristina y se anulaba la de Baldomero Espartero, «a la proclamación del derecho la posesión del símbolo que la legitimaba». Por último, el general Ramón María Narváez, trasladado a Gibraltar, tenía que sublevar Andalucía y la Mancha, en cuanto tuviera noticias de haber tenido éxito la insurrección de Madrid o del País Vasco ${ }^{37}$.

En este plan conspiratorio las provincias Vascongadas y Navarra ocupaban una posición de primer orden, ya que, seguros del triunfo del alzamiento en

35 Este manifiesto de Maria Cristina como el coetáneo del gobierno progresista se encuentran reproducidos en las obras citadas de LAFUENTE, M. y PIRALA, A., respectivamente, en el vol. XXII, págs. 96-97 y vol. VI, págs. 267-277.

36 FLOREZ, José Segundo, Espartero. Historia de su vida militar y política y de los grandes sucesos contemporáneos, vol IV, Madrid 1844-45, pág. 212.

37 LAFUENTE, M., op. cit., vol. XXII, págs. 100-101.

Hispania, LVU2, núm. 193 (1996) 565-586 
las mismas, era el lugar indicado para trasladar a Isabel II en el caso de no poder establecerse en Madrid un gobierno provisional que reemplazara al de Baldomero Espartero, y asf́ «servir en él como bandera de guerra en manos de los conjurados» ${ }^{38}$. Además, era el sitio indicado, precisamente, para la entrada de María Cristina.

También esas provincias y, en concreto, la villa de Bilbao fue el punto primigeniamente escogido por Leopoldo O'Donnell para iniciar el movimiento reaccionario, razón por la que a su regreso de París pidió destino en el cuartel de la misma. Sin embargo, aconsejándole el ministro de la Gobernación. Facundo Infante, que eligiera el mando en cualquiera otra guarnición (incluida Madrid), ya que el gobierno tenía cabal conocimiento que esa villa era un centro de maquinaciones, pudiéndose verse comprometido sin quererlo, el general -jefe de la insurrección conservadora- optó por Pamplona ${ }^{39}$.

De esa manera, el 1 de octubre de 1841 dio comienzo en esa ciudad el levantamiento moderado-fuerista con el alzamiento de Leopoldo $O^{\prime}$ Donnell. Este, que hizo circular una proclama en la que acusaba a Baldomero Espartero de haber usurpado traidoramente la regencia, de atacar a la religión católica y de "haber destruido de hecho los fueros", y en la que garantizaba la conservación integra de los regimenes forales bajo el gobierno de María Cristina, tuvo que contentarse con dominar exclusivamente la ciudadela, ya que a Ja poblacion, con cortas excepciones, le resultaba indiferente que "Cristina estuviera en el palacio o en el ostracismo", mientras, además, el Ayuntamiento de Pamplona, el jefe político (Fernando Madoz) y la Diputación provincial se ponfan al frente de la milicia nacional y de las tropas leales (una vez que Felipe Ribero, virrey de Navarra, se decidio finalmente por el regente) para sofocar la rebelión. Por ello, los notables provinciales más comprometidos con la insurrección, como el banquero Nazario Carraquiri ("que vino desde Madrid, según la opinión pública, con recursos para el movimiento s), el comerciante y ex-diputado a Cortes Juan Pablo Ribed o el barón de Bigüezal, no les quedó otro remedio que constituir en el valle de Echauri un simulacro de Diputación foral, bajo la presidencia del último ${ }^{40}$.

El general Piquero, comandante militar e inspector jefe de la milicia nacional de Alava, no se contentó con permitir que los conspiradores organizaran sus planes, sino que el día 4 secundó en Vitoria el grito dado por Leopoldo O'Donnell en Pamplona, provocando la defección del regimiento de caballería que, a las órdenes del coronel Rijo, el gobierno progresista había enviado a finales del año anterior para reforzar la guarnición de la provincia. Acto seguido, detuvo al corregidor político (Jacinto Manrique), fiel al regente, y cuadriplicó el número de milicianos nacionales, a los que se sumaron los

38 FLOREZ, J. s., op. cit., vol. IV, pág. 253.

39 MARLIANI, E., op. cit., pág. 270 y PIRALA, A., op. cit., vol. VI, págs. $280-281$.

40 Ibid., págs. 279-280 y 306, y vol. VI, págs. 281-284. Además, se puede consultar MaDoz, Fernando, La rebelión de octubre en Pamplona, Madrid 1842 (Referencias: SANCHEZ PRIETO, J. M., op. cit., págs. 691-694). 
miñones movilizados por la Diputación foral que, presidida por el marqués de la Alameda, secundo inmediatamente el alzamiento.

En cuanto Vitoria cayó en manos de la insurrección se instaló una especie de "Gobierno provisional del Reino durante la ausencia de la Reina Gobernadoran, presidido por el general y ex-ministro de Marina, Manuel Montes de Oca, que, llegado de Madrid, estaba revestido de poderes del directorio moderado del que él mismo formaba parte y encargado de organizar el alzamiento de la provincias Vascongadas, así como de disponer lo necesario para recibir en ellas a María Cristina. Para ello designó a Manuel Urioste de la Herrán y al conde de Monterrón comisarios regios, respectivamente, de Vizcaya y Guipúzcoa, encomendándoles ponerse al frente de la sublevación de sus provincias. Al mismo tiempo, superando las promesas realizadas por Leopoldo O'Donnell, Manuel Montes de Oca emitió una proclama en la que, tras recordar la preferencia de las provincias en la revolución de septiembre por «la legitimidad vencida a la usurpación vencedora ${ }^{41}$, no sólo aseguraba el mantenimiento del régimen foral, sino que manifestaba que la ley de 16 de agosto de 1841, promulgada para Navarra, seria derogada y que cualquier modificación foral debía ser establecida por las Juntas generales como «única, exclusiva y legítima representación del país".

A pesar de esas promesas, a pesar de la influencia que se suponía tenían los jefes de la insurrección alavesa, Pedro de Egaña, el marqués de la Alameda (miembros, además, de ese gobierno provisional) y Manuel de Ciorraga, lo cierto es que la opinión pública no se adhirió al movimiento reaccionario con el entusiasmo que era de esperar. Tanto fue así que a medida que empezaron las exigencias en hombres y en dinero para preparar la resistencia, la población alavesa, trasladándose a las posiciones sustentadas por el Ayuntamiento de Vitoria, que desaprobaba la rebelión, impelió al marqués de la Alameda a convocar Juntas extraordinarias. En éstas, declarándose que la provincia no quería una nueva guerra civil, se censuró la conducta del diputado general, obligándole a renunciar al cargo ${ }^{42}$.

Esa disparidad existente en Vitoria entre el Ayuntamiento y la Diputación foral en modo alguno se produjo en Bilbao. Aquí, detenido el general José Santos dela Hera, encargado por el directorio moderado de sublevación de esta villa ${ }^{43}$, fue el comisario regio, Manuel Urioste de la Herrán, apoyado por el coronel del regimiento de infantería de Borbón, Ramón de Larrocha, quien

\footnotetext{
41 A este respecto, Pedro de Egaña, uno de los cabecillas del alzamiento, consideraba posteriomente (en El moderantismo. Carla dirigida Sr. D. Juan Mañe y Flaquer, Barcelona 1879, pág. 27) que este umovimiento de octubre de 1841 y como el posterior de Ciudad Real y Sagunto de 1874 no fueron movimientos revolucionarios: fueron, por el contrario, el restablecimiento del derecho constitucional y dinástico, escandalosamente hollados por los movimientos revolucionarios de 1840 y 1868 .

${ }_{42}$ Sobre el alzamiento alavés hemos seguido LAFUENTE, M., op. cit., vol. XXII, págs. 101-103 y PIRALA, A., op. cit., vol. VI, págs. 285-287. Octubre.

${ }^{43}$ FLOREZ, J. S., op. cit., vol. IV, pág. 236 y Revista de Madrid, I $3^{2}$ ser. (1841) 600: Crónica de 
el día 4, conocidos los sucesos de Pamplona, se puso al frente de los que se habian congregado en el Arenal bilbaino upara sostener con las leyes del país los derechos de María Cristina, Reina Gobernadora de España en el último año escandalosamente atropellada» ${ }^{44}$. Acto seguido, después de encargar a ese coronel la dirección de la comandancia militar de la provincia, tras la dimisión de su comandante, el general José Santa Cruz, y de deponer al corregidor político, Pedro Gómez de la Serna, llamó a la milicia de la villa, que desde la sublevación de septiembre no se había reunido, sumándose asi a los cuatrocientos miqueletes que, con su jefe José de Erezuma al frente, habían secundado la rebelión ${ }^{45}$.

Para defender "esos derechos hollados" inmediatamente se puso a la cabeza del alzamiento la Diputación foral. Así, en la reunión celebrada el día 5 en el salón de sesiones de esta institución - a la que asistieron los miembros de esta corporación, los del Ayuntamiento de Bilbao (con su alcalde, Eulogio de Larrinaga, al frente), padres de provincia (como Gregorio Lezama Leguizamón), los aristócratas y políticos moderados residentes en la villa, los brigadieres Ramón de Larrocha, Francisco de Mazarredo y Antonio de Arana, y otros jefes y oficiales del regimiento de Borbón, el prior del Cabildo eclesiástico y el vicecónsul francés (cuya presencia en un acto de rebelión contra el gobierno no deja de ser digna de notarse) - el diputado general, Domingo Eulogio de la Torre, ante la población reunida en la Plaza Vieja, proclamó a la reina Isabel II, a María Cristina como reina gobernadora del Reino y el restablecimiento de los "venerados» fueros vascongados ${ }^{46}$. Ambas proclamaciones se encontraban estrechamente ligadas porque, como indicaba coetáneamente la Diputación en el llamamiento a los vizcános para que tomaran las armas, lo que estaba en juego era, o la destrucción completa de los fueros o su conservación integra bajo el gobierno de María Cristina:

"(...) La ley 5." del título $1 .^{\circ}$ de nuestros FUEROS manda que todo vizcaíno acuda a las armas en defensa de su Señor. ¿ Qué haréis cuando se trata de defenderle y defender nuestros Fueros ? Si durante la guerra civil reciente habeis dado, aunque divididos, tantas pruebas de herósmo i qué haréis hoy unidos bajo la misma legítima bandera y guiados por vuestras autoridades?. (...) ${ }^{47}$

Esa unión entre los fueros y el trono la reafirmó aún más la Diputación vizcaína al proceder, por un lado, a restaurar los fueros en todo su vigor, que se concretó en la reposición del tribunal foral, y a invitar a Marła Cristina a que a su regreso jurara los fueros «so el árbol sagrado", y al convocar, por otro

\footnotetext{
44 ADFB. Libros de órdenes y circulares... núm. 54. Comunicación de la Diputación foral de Vizcaya y del Ayuntamiento de la villa de Bilbao a la reina Maria Cristina, manifestándole la adhesión al alzamiento, Bilbao, 5-X-1841.

45 El Vascongado, 5-X-1841.

46 Ibid. y ARELLZA, J. M., op. cit., pág. 75-77.

47 ADFB. Libros de órdenes y circulares... núm. 54. Comunicación de la Diputación foral a los vizcaínos, $5-\mathrm{X}-1841$.
}

Hispanie, LVV/2, nưm. 193 (1996) 565-586 
lado, Juntas generales para los días 12, 13 y 14 de octubre con el fin de organizar el armamento general de la provincia en defensa de ambos términos. Actuación que, además, fue corroborada y ampliada por los decretos de 5 y 6 de octubre, promulgados por Manuel Montes de Oca, con los que: se suprimían los tribunales de primera instancia, restituyendo la administración de justicia a las autoridades forales y restableciendo el Corregimiento, para cuya presidencia las Diputaciones vascongadas debían presentar una terna al gobierno provisional; se reintegraba la totalidad de las funciones administrativas a las Diputaciones forales, una vez eliminados los corregidores políticos y las Diputaciones provinciales duplicadas (de Alava y Guipúzcoa, porque en Vizcaya no se había establecido) ${ }^{48}$; se cancelaba la publicación de los boletines oficiales (también de Alava y Guipúzcoa, ya que en Vizcaya no habían salido a la luz de forma continuada desde julio de 1836) ${ }^{49}$; se restablecía el beneficio de bandera de Bilbao. Estas medidas las hizo efectivas en Vizcaya el comisario regio - delegado del gobierno provisional en la provincia-- con: la destitución, ya destacada, del corregidor político el mismo día del alzamiento de la villa; el cese del juez de primera instancia de Bilbao, Juan Celestino Gutiérrez, considerado uno de los jefes del "partido revolucionarion, cuyas funciones eran transferidas a Domingo Eulogio de la Torre que, en calidad de corregidor interino, era sustituido en su cargo de diputado general por el segundo del bando oñacino, José Joaquín de Arguinzóniz; el reemplazo de los tenientes de Corregimiento de Guernica y Durango, Domingo y Rafael Santa Domingo, por Nicolás Ambrosio Anitua y Pedro Manuel de Inchaurrandieta, respectivamente; la separación del juez de contrabando de la villa, Antonio Gómez de Ochoa, y el desplazamiento de sus atribuciones a la propia Diputación foral; la transferencia de las atribuciones del administrador de correos, ejercidas por el también considerado miembro del "partido revolucionario", Toribio Roldán, al coronel Antonio de Arana; etc ${ }^{\text {so }}$.

Hasta tal punto los dirigentes fueristas alzados en Bilbao estaban seguros de la adhesión del resto de los vizcaínos que decidieron enviar al mando del primer diputado general del bando gamboíno, Matfas Izaguirre, una columna formada por miqueletes, milicianos nacionales y tropas del ejército para auxiliar al general Antonio Urbistondo, encargado de la insurrección militar de Guipúzcoa ${ }^{51}$. Aquí, este general con la Diputacion foral sedujeron a las tropas e hicieron de Vergara el foco y asiento de la sublevación, pues en Tolosa se encontraban el comandante militar de la provincia (y de las Vascongadas), Francisco de Paula Alcalá, y el corregidor político, Eustaquio Amilibia, opuestos a la rebelión, y San Sebastián era totalmente adicta al gobierno progre-

\footnotetext{
48 PEREZ NUÑEZ, Javier, «Las Diputaciones provinciales duplicadas de Vizcaya (1839-1871): Euzko-Ikaskuntza Cuadernos de Sección. Historia-Geografia 23 (1995) 167-173.

49 Fernandez sebastian, J., op. cit., págs. 456-458.

so AGSB. Pronunciarniento de Octubre de 1841, reg. 1. Comunicación del comisionado regio, Manuel Urioste de la Herrán, a1 general Manuel Montes de Oca, 9-X-1841.

51 ADFB. Lbros de órdenes y circulares... núm. 54. Circular de la Diputación foral a los vizcainos, 6-X-1841.

Hispania, LVI/2, num. 193 (1996) $565-586$
} 
sista. Así, alli el 10 de octubre se proclamo a María Cristina como reina gobernadora y se instituyó una especie de gobierno provincial que, formado por el general Antonio Urbistondo, el comisario regio, conde de Monterrón, y el diputado general, Francisco Palacios, decreto el día 11 el alzamiento general de los guipuzcoanos con vistas a participar wen el aniquilamiento de un Gobierno impío que persigue la Religión Santa de nuestros padres, derriba Altares y escarnece a los Ministros de su culto; de un Gobierno perjuro que no guarda la fe y palabra empeñados solemnemente; de un Gobierno, en fin, que se había propuesto destruir por sistema todo lo que existe bueno de la Monarquía y con ellas nuestras veneradas instituciones, que por tantos siglos han hecho la felicidad del país» ${ }^{52}$.

De la misma manera que los guipuzcoanos, los fueristas vizcaínos tampoco se alzaron sólo en pro de la conservación integra del régimen foral y de la legitimidad de la ex-reina gobernadora, sino también en defensa del orden, de la legalidad y de la libertad individual, principios que consideraban habían sido perturbados por los progresistas. $Y$, «principalmente, en favor del escarnecido clero español», ya que, "no contento, el gobierno usurpador, con haberles despojado de sus bienes y propiedadesn y haberles convertido «en criados asalariados por los pueblos», estaba "poniendo en duda los dogmas y creencias del catolicismo" ${ }^{53}$. A este respecto, no pueden ser más expresivas las palabras pertenecientes al discurso del corregidor interino, Domingo Eulogio de la Torre, pronunciadas en la sesión de apertura de las Juntas generales de Guernica:

"(...) Las demasías de los que gobernaban a España han conseguido apurar el sufrimiento de los gobernados, que veian reinante el desorden, humillada la autoridad de la ley, olvidada la moral, insultada la religión, mendigando sus ministros, sin decoro el culto, el ejército descuidado y escarnecido, la libertad individual mal protegida, la dignidad nacional ajada y, dominando a los escandalizados y afligidos pueblos, una turba de entes más osados y perversos que la sociedad española encierra, turba que voceando ilimitada libertad ejerce el más puro despotismo. Los amantes del orden, de la moral, de las leyes, de la libertad verdadera, de un trono protector y de un gobierno fuerte y justo, se han concertado y unido, y alzando el grito y tremolando la restauración de la Regencia de la inmortal María Cristina, madre de la Reina nuestra Señora y princesa excelsa, a la cual tanto debe la Nación y de que tanto tiene que esperar el país vascongado. (...) ${ }^{54}$.

Ese intento de captación de los eclesiásticos al alzamiento - «su triunfo es el triunfo de la Religión» - tenía un objetivo concreto, ya que mediante su concurso, contrarrestando los efectos de la proclama emitida en Bourges el 6 de octubre por el pretendiente, Carlos María Isidro, en la que pedía a sus

52 MUGICA, J., op. cit., págs. 269-271.

53 ADFB. Libros de órdenes y circulares... núm. 54. Circular de la Diputación foral a los vizcaínos, 9-X-1841.

54 ADFB. Libros de acuerdos de la Diputación.. núm. 89. Juntas generales, Guernica, 12/14$\mathrm{X}-1841$

Hispania, LVI/2, núm 193 (1996) 565-586 
seguidores que se mantuvieran al margen de una bandera, que no era otra que la de la usurpacion ${ }^{55}$, esperaban atraer a la poblacion vizcaina que se encontraba bastante retraída del movimiento conservador ${ }^{56}$. Así, a pesar de la «espontánea y extraordinaria adhesión de los vizcaínos al noble alzamiento de Bilbao" destacada en las páginas de El Vascongado ${ }^{57}$, a pesar de las optimistas perspectivas del comisario regio, que estimaba que en pocos días se podrían tener levantados y armados 10.000 hombres ${ }^{58}$, lo cierto es que ni el llamamiento de la Diputación foral a sumarse a la causa de la regencia de María Cristina y de los fueros ni la «Junta de Armamento y Defensa" ${ }^{59}$, creada con el fin de centralizar la organización armada, estaban produciendo los efectos deseados.

Frente a esa situación, que por supuesto no alcanzaba las cotas de Guipúzcoa, en donde, a la indiferencia de la población, el movimiento reaccionario se enfrentaba con el hostigamiento de las milicias nacionales, fieles a Baldomero Espartero, de San Sebastián, Irún y Eibar ${ }^{60}$, la asamblea de Guernica en la sesión del día 14 de octubre quiso dar un golpe de timon. Para ello, dispuso, primero, el alistamiento de todos los hombres válidos de diez y ocho a cuarenta años y, segundo, el establecimiento de una "Junta Auxiliar" de la Diputación foral encargada de su organización y armamento ${ }^{61}$. Esta Junta,

35 A pesar de la proclama de Carlos María de Isidro (recogida en A. Pirala, op. cit., vol. VI, págs. 283-284), los ex-ditigentes carlistas vizcaínos Simón de la Torre, Juan Antonio de Verastegui y Castor de Andechaga ofrecieron sus servicios a la Diputación sublevada y participaron en el alzamiento, por lo menos el último. También hay que destacar el apoyo prestado a la insurrección por el escribano de la bandera «Paz y Fueros» durante la guerra carlista precedente, Juan Antonio de Muriagorri, que, además, perdió la vida en un encuentro con las tropas leales.

${ }_{56}$ Existieron excepciones al desinterés general al alzamiento como fue el caso de la ciudad de Orduña, que comunicó el 6 de octubre a la Diputación foral «el levantamiento de la Ciudad por la causa de Isabel $2^{\text {a }}$, por la regencia de su madre y por las instituciones del paíss (ref. en AGSB. Pronunciamiento de Octubre de 1841, reg. 1). PEREZ GALDOS, Benito en sus Episodios Nacionales (concretamente en el 28, titulado Montes de Oca, Madrid, Alianza Editorial, 1978, pág. 133) cita también el pronunciamiento de Portugalete, aunque nosotros dudamos que fuera así, ya que el año anterior habia elegido a Baldomero Espartero como alcalde de la villa.

57 El Vascongado, 8-X-1841.

58 AGSB. Pronunciamiento de Octubre de 1841, reg. 1. Comunicación de comilsario regio de Vizcaya, Manuel Urioste de la Herrán, al general Manuel Montes de Oca, 9-X-1841.

${ }_{59}$ Esta Junta, creada el 8 de Octubre de 1841, estaba formada en sus origenes por: Manuel Urioste de la Herrán (comisario regio), Hipólito Jugo (regidor del Regimiento general), Bonifacio Vildósola (regidor del Ayuntamiento de Bilbao), Antonio de Arana (coronel gobernador de Bilbao) y Pedro Pascual Uhagón, hijo (vocal-secretario). A ella se adhirieron otros personajes influyentes de la provincia como el brigadier Manuel J. del Campillo y el fuerista-tradicionalista Pedro Novia de Salcedo.

60 LASAla y COLLADO, F., op. cit., vol, I, pág. 278.

61 Detrás de ese cambio se encontraba el fracaso en la extensión del movimiento reaccionario de la Junta de Armamento y Defensa, presidida por el cornisario regio. Y de aquí las presiones realizadas por la Diputación foral a Manuel Urioste de la Herrán para que abandonara el puesto de comisario regio, kaquella extraña denominación e investidura que representaba un evidente contrafuero" (ref. en AREILZA, J. M., op. cit., pág. I12).

Hispania, LVI/2, núm. 193 (1996) 565-586 
formada por los prohombres fueristas más caracterizados, fijó su actuación en un doble plano: de una parte, para la articulación del alistamiento general, destacó al frente de cada una de las merindades vizcaínas a uno de sus miembros ${ }^{62}$; de otra parte, para la consecución de los medios necesarios para el armamento y equipo, pidió a la Junta de Comercio de Bilbao un empréstito de dos millones de reales, garantizándoselos con los derechos del tabaco, y acordó convocar al clero "para ver el modo en que podían hacer algún sacrificion, así como ofició a los mandos del ejército para que le suministraran armas ${ }^{63}$.

La marcha de Bilbao el 17 de octubre de un contingente militar al mando del coronel Ramón de Larrocha para apoyar a los sublevados guipuzcoanos ${ }^{64}$ o la decisión el día 18 de esa Junta auxiliar de subdividirse en tres secciones, guerra, hacienda y suministros, previendo una larga lucha ${ }^{65}$, no eran más que la expresión de las vagas informaciones recibidas sobre el fracaso de los alzamientos de Zaragoza, Valladolid y del principal de Madrid. Aquí, centro neurálgico del levantamiento, de cuya suerte dependía el éxito o el menoscabo de todo el movimiento, las cosas no pudieron salir peor. Así, conocidas confusamente el día 5 de octubre las noticias de las sublevaciones de Navarra y de las provincias Vascongadas, los conjurados de la capital, ante las medidas tomadas por el gobierno y por las autoridades de Madrid para hacer frente a la conspiración, tuvieron que alterar algunos de los pasos del plan previsto, fijando su ejecución para el día 7 de ese mes. Limitada la acción a la sublevación de diferentes regimientos de los cuarteles de la villa, el resultado no pudo ser más frustrante, ya que, bien por fallidas adhesiones esperadas de algunos mandos bien por la neutralización de otros de ellos efectuada por el ejecutivo progresista, lo cierto es que sólo se logr6 el concurso del regimiento de la Princesa al mando del general Manuel Gutiérrez de la Concha (uno de los líderes más importantes del alzamiento moderado de Madrid) y, con ello, se redujo el movimiento exclusivamente al intento de estas tropas de tomar el palacio

62 La Junta Auxiliar, constituida el 14 de octubre, tenía al frente de cada una de las merindades a los siguientes personajes: por Uribe, Manuel Maria Murga (propietario-p) y José Ortiz de la Riva (suplente=s); por Busturia, Castor María Allende Salazar (p) y Pedro María Albiz (s); por Arratia y Vedia, Mateo de Eguía (p) y Antonio de Murgoitio (s); por Amorabieta, Martín León de Jaúregui (p) y Juan Dionisio Iturriaga (s); por las Villas y Ciudad, Martín de Jaúregui (p) y Eulogio de Larrínaga (s); por Durango, Antonio de Aguirrebeitia (p) y Santiago Maria de Arguinzóniz (s); por Marquina, Federico Victoria de Lecea (p) y Diego de Mugartegui (s); y por Orozco, Miguel Arrieta de Mascarúa (p) y Bonifacio de Vildósola (s).

63 AGSB. Pronunciamiento de Octubre de 1841, reg. 1. Sesiones de la 1Junta Auxiliar, 15/16$\mathrm{X}-1841$.

64 AREILZA, J. M., op. cit., pág. 78.

65 Las secciones de la Junta Auxiliar, establecidas el 18 de octubre, estaban formadas: la de guerra por Manuel J. del Campillo (brigadier), Antonio de Arana (coronel) y Pedro Pascual Uhagón, hijo; la de hacienda por Manuel María Murga, Pedro de Novia de Salcedo, Federico Victoria de Lecea y Gregorio de Arzabe; y la de suministros por Martín de Jaúregui, Bonifacio de Vildósola, Castor María Allende de Salazar, Mateo de Eguía, Juan Dionisio Iturriaga y Santiago María Arguinzóniz. 
para apoderarse de la reina. Misión imposible, al encontrar una resistencia numantina en el interior de la casa real y al no contar con otras fuerzas de apoyo, de forma que en poco tiempo los sitiadores acabaron convirtiéndose en sitiados por la milicia nacional madrileña y por las tropas fieles al regente. En esta situación la presencia del general Diego de León, jefe del movimiento en la capital y uno de los mandos con más prestigio dentro de las filas del ejército, sólo sirvió para acabar tomando la decisión de proceder a la retirada, en cuya huida además fue detenido con la famosa carta de la ex-regente que le involucraba directamente en el alzamiento ${ }^{6}$.

La confirmación de estos hechos y de la ejecución de algunos de los principales promotores de la sublevación moderada (Diego de León, Borso di Carminatti, Manuel Montes de Oca.), así como de la salida de tropas desde la capital al mando del propio general Baldomero Espartero para sofocar la rebelion de las provincias vascas, mostró como sus poblaciones, que habian sido el más sólido apoyo de la causa carlista, estaban cansadas y, tras una guerra de siete años, nos aspiraban ya más que a vivir en paz ${ }^{67}$. Así, en la villa de Bilbao - el mayor apoyo de la insurrección- el anuncio de la llegada del general Martín Zurbano reveló como el levantamiento y armamento general de la provincia había brillado por su ausencia, como los miqueletes no eran tan fieles a los dictados de la Diputación foral como se pensaba; en definitiva, como el alzamiento se había limitado a unos cuantos militares y a los dirigentes fueristas más sobresalientes, cuya única salida la encontrarían en la huida a Francia, siendo algunos de ellos detenidos en San Sebastián.

«Abandonada la ciudad de Bilbao por las autoridades y la fuerza - relataba la Revista de Madrid-- quisieron algunos enarbolar la bandera del absolutismo y pusieron al efecto, según tenemos entendido, en libertad a los presos de la cárcel; pero el brigadier Zurbano entró en aquélla el día 21 y fusiló a algunos de los que mandados por Castor [de Andechaga] le habian hecho fuego. Con esto pudo ya considerarse totalmente acabada la insurrección de Vizcaya» ${ }^{68}$. Así, tras la despiadada represión infringida en Bilbao por aquél militar, que se saldó con la ejecución de 80 personas poco importantes de la rebelión ${ }^{69}$ y el reemplazo del Ayuntamiento de la villa y de la Diputa-

66 Para el alzamiento de Madrid hemos seguido, fundamentalmente, a LAFUENTE, M., op. cit., vol XXII, págs. 104-112 y PIRALA, A., op. cit, págs. 294-305. En ambas obras se encuentra transcrito el documento comprometedor que le costó la vida al general Diego de León.

67 MARLIANi, E., op. cit., pág. 270.

68 Revista de Madrid, I $3^{2}$ ser. (1841) 595: Crónica de Octubre y Estornes Zubizarreta, Idoia, «1841: un año decisivo»: Muga 1 (1971) 72-73.

69 Continuando con la narración, en la Crónica de Noviembre de la Revista de Madrid [II $3^{\mathrm{a}}$ ser. (1841) 71-74] se destacaba en los siguientes téminos la subyugación a la que se vio sometida la capital vizcaína: «(...) no creiamos ni podiamos creer que se llevase el odio y el castigo hasta el punto en que se ha llegado contra la villa, be en otro tiempo se estrellaron las fuerzas de los carlistas, contra la irvicta Bilbao, donde halló su primer título aristocrático el Regente del Reino. (...) ipero qué importaba eso, cuando sin formación de causa se fusilaba a un joven por el sólo delito de haber hablado mal del comandante de la fuerza armada! Una docena de ambiciosos, decía el Regente en la citada alocución [23 de octubre], eran los que allí habian promovido la sedición y se castiga al pueblo entero. (...)»

Hispania, LVI/2, núm. 193 (1996) 565-586 
ción provincial, que sustituyó a la foral, con personas destacadas del progresismo vizcaino, se establecieron, en primer término, una serie de disposiciones, que englobadas en el estado de sitio que entonces se implantó y que perduró hasta el 11 de diciembre, estaban destinadas a castigar a los culpables directos del alzamiento. Para ello se instituy6 una comisión militar con la misión de juzgar a los instigadores del pronunciamiento, que subsistio hasta el 30 de noviembre, momento en que las causas abiertas pasaron a la jurisdicción civil. Al mismo tiempo el comandante general de las provincias Vascongadas, Francisco de Paula Alcalá, impuso una multa de 6 millones de reales a los individuos de la villa de Bilbao «que trabajaron para promover la rebelión o que directa o indirectamente tomaron parte en ellas, haciendo al Ayuntamiento y a la Diputación provincial directamente responsables de su ejecución ${ }^{70}$.

Tanto de la resolución del juicio, cuya sentencia se pronunció el 16 de junio de $1842{ }^{71}$, como el listado de los multados, que ascendió a $222^{7}$, se puede afirmar que la sublevación de octubre de 1841 en Vizcaya se limito fundamentalmente a la oligarquía fuerista, es decir, a aquellas personas que, pertenecientes a las familias más pudientes y de mayor raigambre de la provincia, dominaban sus instituciones principales, Diputación, Regimiento y Juntas generales, Ayuntamiento y Junta de Comercio de Bilbao. Además, aquí, a diferencia de las otras provincias Vascongadas, no sólo se encontraba casi totalmente atenuada la división entre la burguesía comercial y la aristocracia territorial, sino que podemos ir más lejos e indicar que la unión del bloque dirigente en torno al fuerismo y a la regencia de Marfa Cristina supuso la verdadera materialización entre sus miembros del abrazo de Vergara.

70 AGSB. Alzamiento del País, reg. 1 leg. 24. Disposición del general Francisco de Paula Alcalá, 27-X-1841.

71 Por la sentencia (recogida en El Vizcaíno Originario, 21-VI-1842, núm. 113) sobre la causa abierta a consecuencia del alzamiento de octubre de 1841 en Vizcaya eran condenados a la pena de muerte en garrote y al pago de multas de considerable cuantía: el ex-coronel del regimiento de Borbón, Ramón de Larrocha; el titulado comisario regio, Manuel Urioste de la Herrán; el corregidor interino y diputado general, Domingo Eulogio de la Torre; los diputados generales, Matías Izaguirre y José Joaquín Arguinzóniz; el ex-alcalde de Bilbao, Eulogio de Larrínaga; el ex-regidor del Ayuntamiento de esta villa, Bonifacio de Vildósola; el comandante de la milicia nacional suprimida, Juan Ramón Arana e Hipólito Jugo; el comerciante francés, Pedro Basterreche; el exdiputado a Cortes, Antonio de Benavides; los brigadieres del Convenio de Vergara, Castor de Andechaga y Juan Antonio de Goiri; el ex-alcalde de Durango, Martín de Jaúregui; el ex-capitán del regimiento de Borbón, Calisto de Artaza; el secretario de la Diputación foral, Manuel de Barandica; el comandante de los miqueles, Toribio Ansótegui. A multas de menor cuantía y pena de diez años de prisión de Antonio Alcalá Galiano, pena de ocho años de prisión a Gregorio Lezama Leguizamón, Manuel María de Murga, José Ruet, al ex-general Fermín de Iriarte, al ex-brigadier Manuel J. del Campillo, al exjefe del estado mayor Andrés de Saavedra, pena de seis años de prisión al ex-brigadier Francisco de Mazarredo..

72 AGSB. Alzamiento del País, reg. 1 leg. 43. Certificación de los secretarios de la Comisión Económica de la Provincia de Vizcaya y del Ayuntamiento de Bilbao en orden a las multas y listas de contribuyentes, $25-\mathrm{I}-1842$.

Hispania, LVI2, núm. 193 (1996) 565-586 
En segundo término, Baldomero Espartero aprovechó las circunstancias para reorganizar y, fundamentalmente, democratizar la administración de las provincias Vascongadas. Las razones que le indujeron a realizar estas reformas estaban recogidas en la proclama que realizó el 23 de octubre y en la propia exposición de motivos del decreto de 29 de octubre de 1841, que las contenía: una militar, la necesidad de "dar estabilidad al triunfo" contra la rebelion y terminar con la reiterada actitud amenazante de esas provincias; otra ideológica-política, introducir la revolución liberal desde arriba («debéis ser hombres libres, y lo seréis; os lo prometon), extendiendo los beneficios que la «Ley Fundamentaln concedía a todos y acabando con el dominio exclusivo de una oligarquía; y una última jurídica, aplicar «el principio de la unidad constitucionaln, requerido por los progresistas desde su inclusión en la ley de 25 de octubre de 1839, "sometiendo a cuantas instituciones se le opongan» ${ }^{73}$. De esta forma, se conservaba la legalidad foral establecida por la ley de 25 de octubre de 1839, siendo el decreto de 29 de octubre de 1841 el remedo progresista del desarrollo de la misma, frente al moderado del decreto de 16 de noviembre de 1839. Si éste mantenía intangible el régimen foral, el decreto progresista tendía a reducir la singularidad foral, a uniformarlo con las otras provincias del Estado, a hacer compatibles los fueros con la Constitución.

Ese decreto, por el que se adecuaba la situacion particular de las provincias Vascongadas, no era más que la plasmación del proyecto de ley de 16 de octubre de 1841, ya destacado. Así, se las nivelaba aduanera y judicialmente a las demás provincias de la nación, pero no militar y fiscalmente. También su administración era uniformada: los corregidores políticos eran sustituidos por los jefes políticos, que ostentaban las mismas atribuciones que los otros del Estado; los ayuntamientos se adecuaban a las leyes generales; y se establecía una sola Diputación provincial en cada una de ellas, homologada a las otras de la Monarquía, pero con mayores competencias, al asumir las de las Juntas y Diputaciones generales abolidas. Sin embargo, para el establecimiento definitivo de estas corporaciones hubo que esperar a la ley de 23 de abril de 1842, arrogándose hasta entonces sus funciones el delegado del gobierno asesorado por una comisión económica. Vueltas a instalar, se les agregaron, por el decreto de 14 de julio de ese año, a las atribuciones conferidas por el decreto anterior, las de recaudación del donativo.

3 TOMAS Y VALIENTE, Francisco, Manual de Historia del Derecho Español, Madrid 1981, $3^{\text {a }}$ ed., pág. 572

Hispania, LVI2, núm. 193 (1996) 565-586 